\title{
Perception of Health Challenges, Self-Rated Health and Feeling of Empowerment in a Changing Climate and Environment with Permafrost Thawing
}

\author{
Ulla Timlin ${ }^{1, * \mathbb{D}}$, Sofia Kauppila ${ }^{2}$, Leneisja Jungsberg ${ }^{3,4} \oplus$, Tanja Nordström ${ }^{5,6,7}$, Kirsten Schmidt-Pedersen ${ }^{8}$, \\ Helvi Kyngäs ${ }^{2}$ and Arja Rautio ${ }^{1,9}$
}

1 Arctic Health, Faculty of Medicine, University of Oulu, FI-90014 Oulu, Finland; arja.rautio@oulu.fi

2 Research Unit of Nursing Science and Health Management, Faculty of Medicine, University of Oulu, FI-90014 Oulu, Finland; Pauliina.s.kauppila@mail.student.oulu.fi (S.K.); helvi.kyngas@oulu.fi (H.K.)

3 Institute for Geosciences and Natural Resource Management, Copenhagen University,

1165 Copenhagen, Denmark; leneisja.jungsberg@nordregio.org

4 Nordregio, SE-11186 Stockholm, Sweden

5 Infrastructure for Population Studies, Faculty of Medicine, University of Oulu, FI-90014 Oulu, Finland; tanja.nordstrom@oulu.fi

6 Center for Life Course Health Research, Faculty of Medicine, University of Oulu, FI-90014 Oulu, Finland

7 Medical Research Center Oulu, Oulu University Hospital and University of Oulu, FI-90014 Oulu, Finland

8 Qeqertarsuaq Museum, Qeqertarsuaq, Denmark; kuannitartworks@gmail.com

9 Thule Institute, University of Oulu, FI-90014 Oulu, Finland

* Correspondence: ulla.timlin@oulu.fi; Tel.: +358-50-472-5354

\section{updates}

Citation: Timlin, U.; Kauppila, S.; Jungsberg, L.; Nordström, T.; Schmidt-Pedersen, K.; Kyngäs, H.; Rautio, A. Perception of Health Challenges, Self-Rated Health and Feeling of Empowerment in a Changing Climate and Environment with Permafrost Thawing. Sci 2021, 3 , 28. https://doi.org/10.3390/ sci3020028

Academic Editor: Claus Jacob

Received: 26 March 2021

Accepted: 27 May 2021

Published: 7 June 2021

Publisher's Note: MDPI stays neutral with regard to jurisdictional claims in published maps and institutional affiliations.

Copyright: (c) 2021 by the authors Licensee MDPI, Basel, Switzerland. This article is an open access article distributed under the terms and conditions of the Creative Commons Attribution (CC BY) license (https:/ / creativecommons.org/licenses/by/ $4.0 /)$

\begin{abstract}
Climate change is a global challenge which has direct and indirect health impacts on the lives of people and communities in the Arctic. The aim of our study was to evaluate the perception of permafrost thaw and health challenges and to determine which perceived environmental and adaptation factors relate to self-rated health and, more specifically, to feeling of empowerment when facing the changes and impacts of climate change and permafrost thawing. Questionnaire data ( $n=100)$ were collected from one community located in Greenland, Disko Bay. Data were analyzed by cross-tabulation and the significances were tested either by Pearson's $\chi^{2}$ test, Fisher's exact test or by the t-test, when applicable. Based on these analyses, logistic and linear regression analyses were used to evaluate the associations between demographic variables, challenges posed by permafrost thaw and self-rated health, and associations between feeling of empowerment and perceived environmental/adaptation factors. The results indicated that climate change was not assessed as being a direct risk for the health of local people or their feeling of empowerment. Nature seemed to play an important role for local people, and not being in the natural environment for recreational activities seemed to decrease feeling of empowerment (OR $0.42, p=0.042,95 \%$ CI 0.17-0.97). This paper provides new, multidisciplinary research information about the perception of health challenges, health, and feeling of empowerment among people living in an environment impacted by permafrost thaw and climate change.
\end{abstract}

Keywords: climate change; permafrost thaw; empowerment; health; adaptation; Arctic; indigenous people

\section{Introduction}

A warming climate is a major global problem, and it has serious effects on Arctic areas. It has been demonstrated that air temperature in the Arctic has increased $2.7^{\circ} \mathrm{C}$ during the years 1971-2017 [1]. Ice sheets and glaciers have continued melting, and the decrease in ice sheets in Greenland and the Antarctic has been particularly fast during the years 2002-2011 [2]. The warming climate in the Arctic presents in several ways, such as thawing of permafrost, decreased snow and ice cover, and increased humidity and sea level [1-3]. In addition, permafrost thaw can damage the landscape and infrastructure $[4,5]$. 
Climate change can have comprehensive economic, political, environmental, social, and health impacts on peoples' lives [6,7]. Furthermore, impacts on human health can be related to extreme weather conditions and infectious diseases [8,9]. Diseases can be transmitted to people through water, food, or animals (zoonotic), or diseases can be airborne $[9,10]$. Thus, the impacts of climate change can be divided into direct and indirect effects on health. Direct effects can increase the risk of injuries, even deaths, and are linked to extreme weather and events in the environment, such as storms, floods [11,12], a decrease in ice sheets [6], and destruction of infrastructure or the ecosystem [6,11]. Indirect effects can occur, for example, through diminished water and food security or increased air pollution [6,12]. These effects, both direct and indirect, are related to society and social interactions, and each society can be impacted differently due to its particular situation in the living environment. Eventually, these effects can have further consequences for health, resulting in various physical and infectious diseases and mental health problems [6,11,12].

According to Berry and colleagues [13], the impacts of climate change can be especially serious for people who already live in vulnerable situations, for example Indigenous people. In the Arctic, around 9\% of people are Indigenous [14]. Indigenous peoples live in close connection with the natural environment and their homeland. It is the basis of their cultures, resources and livelihoods. Currently, they are facing rapid changes related to the climate and environment, which have further effects on wellbeing and mental health $[15,16]$. Willox and colleagues [16] have found that negative impacts of climate change, combined with previous life traumas, can have comprehensive impacts on Indigenous peoples' lives and mental health and can lead to a feeling of "powerlessness and loss of control." The feeling of empowerment is closely connected to traditions, values, and independent informed decisions [17].

Climate change requires constant adaptation and mitigation to face coming changes $[18,19]$. The effects of climate change on mental health and adaptation can vary, depending on factors related to culture, available valid information, society and how people are prepared for these changes $[8,20]$. Current research illustrates a knowledge gap in understanding the impacts of climate change and permafrost thaw on health and feeling of empowerment, especially among Indigenous people. It is important to understand and further investigate climate change and its impacts on health $[12,21]$. Furthermore, there is a need for a deeper understanding of perceived empowerment as well [22]. The aim of the study was to evaluate the perception of permafrost thaw and health challenges to determine which perceived environmental and adaptation factors relate to self-rated health and, more specifically, to the feeling of empowerment when facing the changes and impacts of climate change and permafrost thaw. The case area of the study was in Greenland, where the majority of people, around 90\%, are Indigenous [14]. It is important to gather more scientific knowledge about Indigenous peoples' lives in Greenland, where the environment is surrounded by climate change, since much research providing essential information about Indigenous people and climate change has focused on Alaska or Northern Canada, i.e., [16,23-26].

\section{Materials and Methods}

A questionnaire was developed for this multidisciplinary project as there were no previous surveys that could have been used for this specific need. The developed questionnaire was translated from English into Greenlandic and pre-tested. Local knowledge was utilized when translating the questionnaire, and also while pre-testing, in order to maintain cultural and linguistic sensitivity. Some minor changes were made in order to develop questions and ensure clarity, for example, the order of two questions (Q 1 and Q 2, see Supplement S1) was reorganized and more answer options were included for another question (not included in this current study). The multidisciplinary research team collected the data using one shared questionnaire. This was ethical and respectful towards the local people because the researchers were able to collect the data all at once. Our research plan did not meet the criteria for medical research, and it did not require ethical approval on human sciences according to the Finnish National Board on Research Integrity TENK [27]. 
The research group has ethical approval from the Health Research Ethical Committee in Greenland for further research.

\subsection{Data Collection}

Data were collected from one community located in the Disko Bay area of Greenland. The community has around 1000 residents (including approximately 200 residents under 18 years old) and is located in an area of continuous and discontinuous permafrost thaw [14]. For data collection, a local research assistant was hired in cooperation with the Arctic Station of the University of Copenhagen. Data collection was conducted face-to-face between February-April 2019, using printed questionnaires which participants filled out independently. Participation was voluntary, and only persons aged 18 years old or older were recruited for the study. Participants gave oral consent to participate, and they were able to refuse, dismiss questions, or terminate the study process at any time. The results reported in this paper are based on the printed questionnaire.

Prior to data collection, the research assistant was trained to collect the data. The survey was tested by the research assistant, who went through the survey and adjusted two of the questions and changed the order of the first and second question as it would make better sense that way. After collecting the first five questionnaires, it was discussed how the questions were received and whether valid and reliable survey answers were obtained. The discussion confirmed that valid answers on peoples' experiences of the social impacts of permafrost were obtained, and that people felt safe to share reliable information about their experiences on the changes in the permafrost grounds. Throughout collecting the remaining survey answers, a close dialogue with the research assistant continued to assure us that the collected answers were valid and reliable. The goal was to recruit participants with an equal balance of age, gender, and profession. Local knowledge was essential to achieve this goal. The data were collected utilizing snowball sampling and the local research assistant's knowledge of the community.

\subsection{Statistical Analysis}

\subsubsection{Questionnaire and Independent Variables}

The questionnaire was divided into three parts: Changes related to permafrost thaw in the surrounding environment that impacts local peoples' lives; impacts of permafrost thaw on hunting, fishing, and harvesting; and questions related to participants (demographic part). From the questionnaire, the questions related to being in nature, challenges associated with life and the environment, adaptation, and background variables, such as age and main profession were chosen for statistical analysis to explain self-rated health and feeling of empowerment. These specific questions are presented in the Supplement S1.

\subsubsection{Analysis and Dependent Variables}

Participants assessed their self-rated health on a scale from 1-100\%. The original scale was used in the statistical analysis for the evaluation of perceptions of health challenges. For the further statistical analysis, the health variable was classified into three classes: low $(0-33 \%)$, medium (34-66\%), and high (67-100\%) and used as a dependent variable. Furthermore, a feeling of being empowered to face changes (yes) compared to not clearly having a feeling of empowerment (no, somewhat) was used as a dependent variable in the analysis. This classification was made since over half of the participants $(54 \%)$ assessed that they clearly felt empowered to face changes (Table 1). This report concentrates on these variables; however, results from the original classification of empowerment (no, somewhat, yes) are presented in Supplement S2 of Table S1. In the statistical analyses, missing values were kept as missing values. 
Table 1. Demographic variables.

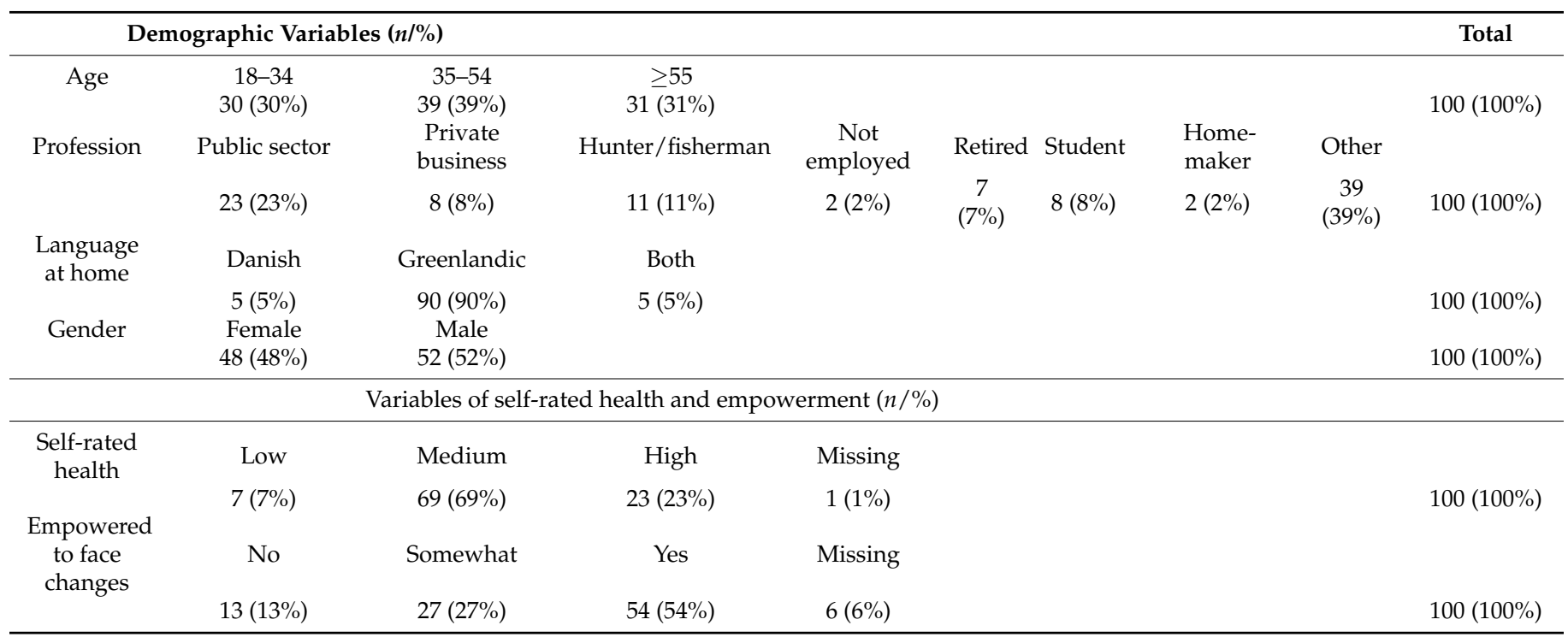

The statistical analysis started with an investigation into the perceptions of permafrost thaw and health challenges. First, the frequencies and associations between human health challenges (Question 5) and demographic variables (age, gender, profession) were investigated. Second, the associations between self-rated health and the assessment of whether thawing has led to positive or negative changes during the past 10 years (Question 3) and whether permafrost is causing problems (Question 4) were evaluated using the t-test. Analysis continued from logistic regression analysis to complete univariate and multivariate analyses adjusted for gender, age, and profession. Nominal (Question 5) logistic regression analyses was used to calculate odds ratios (OR) with $95 \%$ confidence intervals ( $95 \% \mathrm{CI}$ ), while linear (self-rated health) regression provided the $\beta$ and $95 \%$ CI. In the statistical analysis, Question 5 was analyzed using the original classification, but it was also reclassified into three groups: not important, a little important/important, very important/I don't know. For the age variable, the original classification and reclassification were used in the statistical analysis.

The statistical analysis continued with the investigation of reclassified self-rated health and feeling of empowerment. Relationships between all independent variables (see Supplement S1 were analyzed by cross-tabulation, and the significances were tested either by Pearson's $\chi^{2}$ test or by Fisher's exact test. Based on these analyses, a binary logistic regression analysis (enter method) was used to evaluate the associations between feeling of empowerment to face changes related to permafrost thaw and perceived environmental and adaptation factors. The analysis included two steps: first, a univariate analysis, followed by a multivariate analysis adjusted for demographic variables (age, gender, language, employment situation). Before completing the binary logistic regression analysis, the correlations between the independent variables were checked, based on Spearman's rank correlation coefficient value. Variables having an association with either self-rated health or empowerment with a $p$-value $\leq 0.1$ were chosen for a logistic regression model of feeling of empowerment, including all variables/choices of the original question. All variables associated with a dependent variable $(p$-value $\leq 0.1)$ are presented in the Supplement S2 of Table S1.

The data were analyzed using IBM SPSS Software, version 25. All tests were two-tailed, and $p$-values less than 0.05 were considered statistically significant. In addition, the Bonferroni correction approach was used in each question to control for multiple comparisons. 


\section{Results}

\subsection{Characteristics of the Participants}

In total, 100 local people participated in this study: 48 women and 52 men. The participants aged 35-54 years $(n=39,39 \%)$ formed the largest group. Almost all of the participants $(n=90,90 \%)$ spoke Greenlandic at home, and 69\% $(n=69)$ of participants assessed their health as being at a medium level (Table 1). None of the demographic variables (age, gender, profession, language at home) were significantly associated with self-rated health or feeling of empowerment. Most commonly, participants chose increasing air temperature as being the main cause of the thawing of the frozen ground $(n=77,77 \%)$, followed by increased ground temperature $(n=40,40 \%)$ and decreases in snow depth $(n=13,13 \%)$.

\subsection{Perception of Permafrost Thaw and Health Challenges}

Originally, participants rated their health on a scale from 1 to 100; the mean value was 58 and median value was 50 (SD 21). Age, gender and occupation were not associated with either experiences of permafrost thaw or self-rated health.

Around a third of the participants $(n=37,37 \%)$ considered thawing of the frozen ground to be important in explaining challenges associated with human health, compared to those who did not $(n=11,11 \%)$. However, just over half of the participants $(n=52,52 \%)$ answered I don't know to this question. Gender $(p=0.265)$, age $(p=0.275)$, and profession $(p=0.652)$ were not associated with how respondents assessed challenges associated with human health. Of the participants, $65 \%(n=65)$ reported that the thawing of the frozen ground has led to negative changes, $15 \%(n=15)$ thought the changes were positive and $20 \%(n=20)$ were missing information. Of the participants, $21 \%(n=21)$ reported that they had experienced problems as a result of the thawing, while the majority did not $(n=66$, $66 \%)$, and a minority of participants $(n=13,13 \%)$ were undecided.

Reporting negative changes related to permafrost thaw during the past 10 years was not associated with self-rated health $(\beta 0.5,95 \%$ CI $[-9,15])$ compared to those who considered that permafrost thawing to lead to positive changes. Considering that thawing of the permafrost caused problems to the participant was not associated with how they evaluated their self-rated health $(\beta-0.5,95 \% \mathrm{CI}[-9,6])$ compared to those who reported that they experienced no problems as a result of permafrost thawing.

\subsection{Associations with Self-Rated Health and Empowerment}

Table 2 presents the associations between self-rated health and feeling of empowerment. Challenges associated with the physical environment correlated with self-rated health $(p=0.048)$. Of those who rated their health at a medium level, almost half of participants $(n=23,47 \%)$ felt that challenges to the physical environment were less important, while $18 \%(n=12)$ felt that these challenges were very important. However, $35 \%(n=24)$ who rated their health at a medium level answered I don't know to this question.

Challenges associated with housing, buildings, and roads were also significantly associated with self-rated health $(p=0.010)$. A majority with a medium level of self-rated health $(n=40,60 \%)$ assessed that challenges associated with housing, buildings and roads as either important or very important, compared to those who assessed that challenges were either not important or only a little important $(n=4,6 \%)$. Still, 34\% $(n=23)$ answered I don't know.

Being in the natural environment for recreational activities was associated with a feeling of being empowered to face changes $(p=0.056)$. Participants who assessed being empowered were in nature for recreational activities very often $(n=37,69 \%)$, compared to those who participated less often $(n=17,31 \%)$. However, this association was not statistically significant. Still, a majority who expressed empowerment to face changes were not often in nature for economic activities $(n=42,78 \%$ ), compared to those who were very often $(n=10,18 \%, p=0.003)$. Participants who did not clearly feel empowered to face changes were not in nature for economic activities $(n=40,100 \%)$. (See Table 2.) 
Table 2. Associations with feeling of empowerment and self-rated health $(p \leq 0.06)$.

\begin{tabular}{|c|c|c|c|c|c|c|c|c|}
\hline \multicolumn{9}{|c|}{ Self-Rated Health } \\
\hline & \multicolumn{2}{|c|}{ Low } & \multicolumn{2}{|c|}{ Medium } & \multicolumn{2}{|c|}{ High } & \multirow[b]{2}{*}{$p$-Value } & \multirow[b]{2}{*}{ Effect Size $* *$} \\
\hline & $n$ & $(\%)$ & $n$ & $(\%)$ & $n$ & $(\%)$ & & \\
\hline \multicolumn{9}{|l|}{$\begin{array}{l}\text { Challenges are associated with housing, } \\
\text { buildings, roads }(n=96)\end{array}$} \\
\hline \multirow{3}{*}{$\begin{array}{l}\text { not important, little important } \\
\text { important, very important } \\
\text { I don't know }\end{array}$} & 0 & (0) & 4 & $(6)$ & 5 & (23) & 0.010 & $0.264^{b}$ \\
\hline & 1 & (4) & 40 & $(60)$ & 11 & $(50)$ & & \\
\hline & 6 & (86) & 23 & (34) & 6 & (27) & & \\
\hline \multicolumn{9}{|l|}{$\begin{array}{l}\text { Challenges are associated with physical } \\
\text { environment }(n=98)\end{array}$} \\
\hline \multirow{6}{*}{$\begin{array}{l}\text { not important, little important, important } \\
\text { very important } \\
\text { I don't know }\end{array}$} & 2 & (29) & 23 & $(47)$ & 7 & $(30)$ & 0.048 & $0.225^{b}$ \\
\hline & 0 & 0 & 12 & (18) & 9 & $(40)$ & & \\
\hline & 7 & $(71)$ & 24 & (35) & 7 & (30) & & \\
\hline & \multicolumn{6}{|c|}{ Feeling of empowerment } & & \\
\hline & \multicolumn{2}{|c|}{ no, somewhat } & \multicolumn{2}{|c|}{ yes } & & & & \\
\hline & $n$ & $(\%)$ & $n$ & $(\%)$ & & & $p$-value & \\
\hline \multicolumn{9}{|l|}{$\begin{array}{l}\text { Being in natural environment for } \\
\text { economic activities }(n=94)\end{array}$} \\
\hline never, rarely, sometimes & 40 & $(100)$ & 42 & $(78)$ & & & $0.003 *$ & $0.329^{b}$ \\
\hline very often & 0 & $(0)$ & 10 & (18) & & & & \\
\hline $\mathrm{N} / \mathrm{A}$ & 0 & $(0)$ & 2 & $(4)$ & & & & \\
\hline \multicolumn{9}{|l|}{$\begin{array}{l}\text { Being in natural environment for } \\
\text { recreational activities }(n=94)\end{array}$} \\
\hline never, rarely, sometimes & 21 & (53) & 17 & $(31)$ & & & 0.056 & $0.212^{\mathrm{a}}$ \\
\hline very often & 19 & (47) & 37 & (69) & & & & \\
\hline \multicolumn{9}{|c|}{ * Remained statistically significant after Bonferroni correction, ${ }^{* *}$ Cramer's V: ${ }^{\text {a }}$ Small effect; ${ }^{b}$ Medium effect. } \\
\hline \multicolumn{9}{|c|}{$\begin{array}{l}\text { 3.4. Associations between Feeling of Empowerment and Perceived Environmental and } \\
\text { Adaptation Factors }\end{array}$} \\
\hline \multicolumn{9}{|c|}{$\begin{array}{l}\text { Table } 3 \text { presents the results of the binary logistic regression analysis examining associ- } \\
\text { ations with having feeling of empowerment. Based on univariate regression analysis, not } \\
\text { being in the natural environment for recreational activities (OR } 0.42,95 \% \text { CI }[0.18,0.97] \text {, } \\
p=0.042 \text { ) or economic activities (OR } 0.30,95 \% \text { CI }[0.09,1.00], p=0.050) \text { seemed to decrease } \\
\text { the odds of a clear feeling of empowerment to face the changes caused by permafrost } \\
\text { thawing, compared to participants who were in nature often for recreational or economical } \\
\text { activities. Participants who informed us that challenges associated with housing, buildings, } \\
\text { and roads were less important for them had lower feeling of empowerment (OR } 0.32,95 \% \\
\text { CI [0.10, } 1.04], p=0.058) \text { compared to those who assessed these infrastructure challenges as } \\
\text { very important. This association was not statistically significant. Associations based on } \\
\text { multivariate analysis were also not significant. }\end{array}$} \\
\hline
\end{tabular}


Table 3. Associations of feeling of empowerment $(p \leq 0.1)$.

\begin{tabular}{|c|c|c|c|c|}
\hline & Yes $(n / \%) /$ Total & OR & $95 \%$ CI & $p$-Value \\
\hline Variables & \multicolumn{4}{|c|}{ Feeling of empowerment } \\
\hline \multicolumn{5}{|l|}{ Being in nature for economical activities ${ }^{a}$} \\
\hline never, rarely & $38(51 \%) / 74$ & 0.30 & $0.09-1.00$ & 0.050 \\
\hline sometimes, very often & $14(78 \%) / 18$ & Ref. & & \\
\hline \multicolumn{5}{|c|}{ Model statistics AIC123.601; $R^{2} 0.062$} \\
\hline \multicolumn{5}{|l|}{ Being in nature for recreational activities ${ }^{a}$} \\
\hline never, rarely, sometimes & $17(45 \%) / 38$ & 0.42 & $0.18-0.97$ & 0.042 \\
\hline very often & $37(66 \%) / 56$ & Ref. & & \\
\hline \multicolumn{5}{|c|}{ Model statistics AIC $126.000 R^{2} 0.059$} \\
\hline \multicolumn{5}{|l|}{ Challenges associated with physical environment ${ }^{a}$} \\
\hline not important, little important, important & $19(49 \%) / 39$ & 0.32 & $0.10-1.04$ & 0.058 \\
\hline very important & $15(75 \%) / 20$ & Ref. & & \\
\hline \multicolumn{5}{|c|}{ Model statistics AIC 78.533; $R^{2} 0.086$} \\
\hline \multicolumn{5}{|l|}{ Being in nature for economical activities $b$} \\
\hline never, rarely & $38(51 \%) / 74$ & 0.33 & $0.10-1.10$ & 0.072 \\
\hline sometimes, very often & $14(78 \%) / 18$ & Ref. & & \\
\hline \multicolumn{5}{|c|}{ Model statistics AIC 129.801; $R^{2}$ 0.087; HL: $\chi^{2} 7.795$, df 7, $p 0.351$} \\
\hline \multicolumn{5}{|l|}{ Being in nature for recreational activities $b$} \\
\hline never, rarely, sometimes & $17(45 \%) / 38$ & 0.42 & $0.17-1.01$ & 0.053 \\
\hline very often & $37(66 \%) / 56$ & Ref. & & \\
\hline \multicolumn{5}{|c|}{ Model statistics AIC 131.636; $R^{2} 0.9 ; H L: \chi^{2} 3.441$, df 8, p 0.904} \\
\hline \multicolumn{5}{|l|}{ Self-rated health ${ }^{c}$} \\
\hline low & $2(40 \%) / 5$ & & & \\
\hline medium & $35(54 \%) / 65$ & 0.39 & $0.14-1.14$ & 0.086 \\
\hline high & $17(74 \%) / 23$ & Ref. & & \\
\hline \multicolumn{5}{|c|}{ Model statistics AIC125.378; $R^{2}$ 0.072; HL: $\chi^{2} 1.358$, df 3, p 0.673} \\
\hline
\end{tabular}

${ }^{a}$ Univariate analysis, ${ }^{b}$ Adjusted for age, gender, language, employment situation, ${ }^{c}$ Adjusted for self-rated quality of life, Abbreviations: AIC: Akaike information criterion; $\mathrm{R}^{2}$ : Nagelkerke $\mathrm{R}^{2}$; Hosmer-Lemeshow goodness-of-fit test (HL). After Bonferroni correction, none of the results were statistically significant.

\section{Discussion}

Based on the study completed by Cardwell and Elliot [28], a minority of participants felt their living environment was connected to their own health or the health of the community. However, acute or concrete environmental problems were recognized better as being related to health [28]. This could explain the results of the current study as well. A majority of participants whose self-rated health was not at a high level saw challenges associated with the physical environment as less important. In addition, challenges associated with modern infrastructure were considered more important by participants with medium and high health levels. Further, not seeing these challenges as very important seemed to decrease the feeling of empowerment to face changes. It can also be the case that nature and being in nature are important, even if changes in nature are visible for people who spend time there. It can be that these specific changes were recognized and people were ready to act on them in order to improve the situation. In their study completed in New Zealand, Aitken and colleagues [29] found that a greater feeling of powerlessness was associated with peoples' actions regarding climate change. The more powerless people felt, the more likely they were to see their own actions against climate change as less important. At the same time, they felt uncertain about the significance of climate change [29]. Similarly, Hartmann and colleagues [22] found that people who felt empowered were more active in their preventive behavior with climate change. 
Based on the results, permafrost thawing was not associated with self-rated health. The relatively good self-rated health observed was in line with the findings of a previous study on self-rated health among young Indigenous people in Greenland and Norway [30]. The results indicate that the living environment and nature have an important role in supporting the feeling of empowerment of the participants. This finding is supported by previous research that nature and the surrounding environment are very important for Indigenous peoples [31]. Their homeland and connection to nature are essential for Indigenous peoples to practice their own culture and livelihoods [17,32]. Being connected to nature and spending time on the land are thought to have healing benefits [31]. Changes in the natural environment might therefore be hypothesized to cause problems with perceived health or well-being. However, the positively perceived self-rated health observed and the lack of association between permafrost thaw and self-rated health do not support this hypothesis. Even though health problems related to permafrost thaw have been recognized in past research [33], it may be that permafrost thaw was not seen as such a threat that it would negatively affect the perceived health of the people living in the study area. Another possible explanation is that permafrost thaw may not, indeed, be a major problem for the study participants. Some areas of Disko Bay are located between continuous and discontinuous zones of permafrost, and this may have influenced the results of this study. Almost half of the participants (40\%) did not clearly feel that they were empowered to face the challenges of climate change and permafrost thaw. According to the study by Cunsolo Willox and colleagues [16], people in North Canada experienced increased family stress, substance use and a variety of mental health challenges due to limited access to nature and changes in their living environments caused by climate change. Many events which occur due to climate change are fast, but things can change gradually over time and still have an impact on mental health $[8,11]$. Especially, the loss of animal or plant species due to climate change can cause a lack of hope [8].

Climate change has been found to affect the traditional living ways of Arctic Indigenous peoples and their ability to maintain healthy lifestyles. These impacts are related to demographic factors such as age, gender, individual health situation, and economic situation [18]. Interestingly, none of the demographic factors (age, gender, professional situation) were associated with self-rated health or feeling of empowerment in the current study. Still, based on the results, the majority of participants who felt empowered to face changes were not much in the natural environment for economic activities. The tourism business in the Arctic is based on the natural environment, which can be in a vulnerable situation nowadays [34]. According to Statistics in Greenland [35], the tourism business in the Disko Bay area has grown rapidly.

Overall, a warming climate with several impacts can result in mental health problems. It can affect physical health as well as community health [13]. All changes require an ability to adapt to the situation, and successful adaptation can finally provide a possibility to strengthen the culture and livelihoods of Indigenous peoples [15]. Nuttall [36] investigated climate change in Greenland and the lives of peoples surrounded by changes. In addition to adaptation and resilience, Nuttall suggested including anticipation in the discussion. It is important to understand how people are able to anticipate climate changes and see the impacts as not only negative, but also positive, in that they can provide new opportunities [36]. While changes due to a warming climate require ongoing adaptation from individuals and communities, there are certain ways to handle the situation and capacities can differ between communities [6].

Overall, adaptation requires several elements, such as cooperation and communication between communities, people, leaders and politician representatives, knowledge and resources, preparedness, and actions [15,20]. However, adaptation is not endless-at some point it can stop [21]. Communities require valid information and education in order to understand, prepare for, and deal with changes and make relevant decisions. This requires communication and cooperation between national health agencies, policy makers, and local health services $[28,37,38]$. It also requires the work of researchers-scientific knowledge 
and information are essential when processing the impacts of climate change. It needs to be recognized that the mental effects of climate change are related to the capacity to adapt and the empowerment of local communities and their people [39].

Our results demonstrate that the challenges associated with environment and modern infrastructure were recognized. These results do not identify a direct risk for health or empowerment, but they may have indirect impacts on health and empowerment, and whether people feel they have control over their lives. Overall, the results of the study can be affected by the living environment, and permafrost thawing is not necessarily a problem in the study subjects' living area due to the discontinuous zone of permafrost. On the other hand, local people may have already slowly adapted to changes in the climate over time. They have comprehensive, valid knowledge and experiences that can be utilized with climate change. Our results provide an overall description of health challenges, selfrated health, and feeling of empowerment in an environment and community that has recognized changes due to climate change and permafrost thaw.

This research has limitations that should be acknowledged. The data sample was fairly small, and results cannot be generalized. After the Bonferroni correction, the majority of the results were not statistically significant. The small sample size with a large amount of missing information could have an effect on some specific questions. For example, in Q5 "Perception of health challenges," a majority of the participants (52\%) answered I don't know to this question and one-fifth of the participants (20\%) did not answer Q4, which asked whether permafrost thaw has led to positive or negative changes. This may have impacted the statistical analyses. However, it may be that participants would have needed more time to answer on these questions in order to avoid missing information, or it could be that they did not recognize these problems as a part of their lives and it was challenging to assess them. Overall, a larger sample size would have provided more power on the statistical analyses, and more specifically on the multivariate regression analysis. Overall, the goodness of fit of the models was mediocre. More research is required with a larger data sample in order to generalize the results and to avoid such occurrences. However, settlements in Greenland are small, which can put challenges on collecting data with a larger sample size. The strengths of the research are in the multidisciplinary teamwork, joint questionnaire, and data collection. By collecting all the data at once, the burden on local people was limited and the data was able to be collected in a multidisciplinary way. In addition, the results can provide information about indirect health and mental health impacts.

\section{Conclusions}

Based on the results, feeling of empowerment increased when individuals spent time in the natural environment for recreational activities. Although this finding was not statistically significant, results suggests that overall, the natural environment is important for local people and it supports their feeling of empowerment. Challenges associated with participants' lives were recognized, and recognizing challenges associated with modern and built infrastructure was especially important for their feeling of empowerment. Still, climate change and permafrost thawing do not appear as direct risks for the health of local people, nor to their feeling of empowerment in this study. More research is needed in order to understand this issue more comprehensively. This issue requires close multidisciplinary research and cooperation between researchers in order to achieve a comprehensive understanding of different disciplines, for example, social sciences and natural sciences. A multidisciplinary approach also allows the possibility to gather information together and holistically describe changes and impacts, thereby giving a voice to the communities. The information could be used to support stronger cooperation between local representatives and politicians and health care organizations in order to increase the capacity of adaptation and provide relevant information for decision-making. 
Supplementary Materials: The following are available online at https:/ / www.mdpi.com/article/10 .3390 / sci3020028/s1, Supplement S1 and Supplement S2 of Table S1: Associations with feeling of empowerment and self-rated health $(p \leq 1.0)$.

Author Contributions: Conceptualization, L.J., and K.S.-P.; methodology, U.T., S.K., L.J., T.N., H.K., A.R.; formal analysis, U.T., S.K., T.N., H.K., A.R.; investigation, L.J. and K.S.-P.; writing-original draft preparation, U.T. and S.K.; writing-review and editing, all authors. All authors have read and agreed to the published version of the manuscript.

Funding: This publication is part of the Nunataryuk project. The project received funding under the European Union's Horizon 2020 Research and Innovation Programme under grant agreement no. 773421.

Institutional Review Board Statement: Not applicable. Our research plan did not meet the criteria for medical research and it did not require ethical approval on human sciences according to the Finnish National Board on Research Integrity, TENK.

Informed Consent Statement: Informed consent was obtained from all subjects involved in the study.

Data Availability Statement: Not applicable.

Conflicts of Interest: The authors declare no conflict of interest.

\section{References}

1. Box, J.E.; Colgan, W.T.; Christensen, T.R.; Schmidt, N.M.; Lund, M.; Parmentier, F.-J.W.; Brown, R.; Bhatt, U.S.; Euskirchen, E.S.; Romanovsky, V.E.; et al. Key indicators of Arctic climate change: 1971-2017. Environ. Res. Lett. 2019, 14, 045010. [CrossRef]

2. IPCC. Climate Change 2014: Synthesis Report. Contribution of Working Groups I, II and III to the Fifth Assessment Report of the Intergovernmental Panel on Climate Change; Pachauri, R.K., Meyer, L.A., Eds.; IPCC: Geneva, Switzerland, 2014; 151p.

3. Stern, G.A.; Macdonald, R.W.; Outridge, P.M.; Wilson, S.; Chételat, J.; Cole, A.; Hintelmann, H.; Loseto, L.L.; Steffen, A.; Wang, F.; et al. How does climate change influence arctic mercury? Sci. Total Environ. 2012, 414, 22-42. [CrossRef]

4. Farquharson, L.M.; Romanovsky, V.E.; Cable, W.L.; Walker, D.A.; Kokelj, S.V.; Nicolsky, D. Climate Change Drives Widespread and Rapid Thermokarst Development in Very Cold Permafrost in the Canadian High Arctic. Geophys. Res. Lett. 2019, 46, 6681-6689. [CrossRef]

5. Schaefer, K.; Lantuit, H.; E Romanovsky, V.; Schuur, E.A.G.; Witt, R. The impact of the permafrost carbon feedback on global climate. Environ. Res. Lett. 2014, 9, 085003. [CrossRef]

6. McMichael, A.J. Globalization, Climate Change, and Human Health. N. Engl. J. Med. 2013, 368, 1335-1343. [CrossRef]

7. Whiteman, G.; Hope, C.; Wadhams, P. Vast costs of Arctic change. Nat. Cell Biol. 2013, 499, 401-403. [CrossRef] [PubMed]

8. Cianconi, P.; Betrò, S.; Janiri, L. The Impact of Climate Change on Mental Health: A Systematic Descriptive Review. Front. Psychiatry 2020, 11, 74. [CrossRef] [PubMed]

9. Hambling, T.; Weinstein, P.; Slaney, D. A Review of Frameworks for Developing Environmental Health Indicators for Climate Change and Health. Int. J. Environ. Res. Public Health 2011, 8, 2854-2875. [CrossRef] [PubMed]

10. Ebi, K. Climate Change and Health Risks: Assessing And Responding To Them Through 'Adaptive Management'. Health Aff. 2011, 30, 924-930. [CrossRef]

11. Bourque, F.; Willox, A.C. Climate change: The next challenge for public mental health? Int. Rev. Psychiatry 2014, 26, 415-422. [CrossRef]

12. Watts, N.; Adger, W.N.; Agnolucci, P.; Blackstock, J.; Byass, P.; Cai, W.; Chaytor, S.; Colbourn, T.; Collins, M.; Cooper, A.; et al. Health and climate change: Policy responses to protect public health. Lancet 2015, 386, 1861-1914. [CrossRef]

13. Berry, H.L.; Bowen, K.; Kjellstrom, T. Climate change and mental health: A causal pathways framework. Int. J. Public Health 2010, 55, 123-132. [CrossRef] [PubMed]

14. Jungsberg, L.; Turunen, E.; Heleniak, T.; Wang, S.; Ramage, J.; Roto, J. Atlas of Population, Society and Economy in the Arctic; Nordregio Working Paper; Nordregio: Stockholm, Sweden, 2019; Volume 3.

15. Ford, J.D. Indigenous Health and Climate Change. Am. J. Public Health 2012, 102, 1260-1266. [CrossRef]

16. Cunsolo Willox, A.; Harper, S.L.; Ford, J.D.; Edge, V.L.; Landman, K.; Houle, K.; Blake, S.; Wolfrey, C. Climate change and mental health: An exploratory case study from Rigolet, Nunatsiavut, Canada. Clim. Chang. 2013, 121, 255-270. [CrossRef]

17. Chatwood, S.; Paulette, F.; Baker, G.R.; Eriksen, A.M.A.; Hansen, K.L.; Eriksen, H.; Hiratsuka, V.; Lavoie, J.; Lou, W.; Mauro, I.; et al. Indigenous Values and Health Systems Stewardship in Circumpolar Countries. Int. J. Environ. Res. Public Health 2017, 14, 1462. [CrossRef] [PubMed]

18. McClymont Peace, D.; Myers, E. Community-based Participatory Process-Climate Change and Health Adaptation Program for Northern First Nations and Inuit in Canada. Int. J. Circumpolar Health 2012, 71, 1-8. [CrossRef]

19. Patz, J.A.; Frumkin, H.; Holloway, T.; Vimont, D.J.; Haines, A. Climate change: Challenges and opportunities for global health. JAMA 2014, 312, 1565-1580. [CrossRef] [PubMed] 
20. Hayes, K.; Blashki, G.; Wiseman, J.; Burke, S.; Reifels, L. Climate change and mental health: Risks, impacts and priority actions. Int. J. Ment. Health Syst. 2018, 12, 1-12. [CrossRef] [PubMed]

21. Watts, N.; Amann, M.; Ayeb-Karlsson, S.; Belesova, K.; Bouley, T.; Boykoff, M.; Byass, P.; Cai, W.; Camp-bell-Lendrum, D.; Chambers, J.; et al. The Lancet Countdown on health and climate change: From 25 years of inac-tion to a global transformation for public health. Lancet 2018, 391, 581-630. [CrossRef]

22. Hartmann, P.; Apaolaza, V.; D'Souza, C. The role of psychological empowerment in climate-protective consumer behaviour: An extension of the value-belief-norm framework. Eur. J. Mark. 2018, 52, 392-417. [CrossRef]

23. Brubaker, M.; Berner, J.; Chavan, R.; Warren, J. Climate change and health effects in Northwest Alaska. Glob. Health Action 2011, 4, 8445. [CrossRef]

24. Cunsolo Willox, A.; Harper, S.L.; Ford, J.D.; Landman, K.; Houle, K.; Edge, V.L. "From this place and of this place:" climate change, sense of place, and health in Nunatsiavut, Canada. Soc. Sci. Med. 2012, 75, 538-547. [CrossRef]

25. Ford, J.D.; Berrang-Ford, L.; King, M.; Furgal, C. Vulnerability of Aboriginal health systems in Canada to climate change. Glob. Environ. Chang. 2010, 20, 668-680. [CrossRef] [PubMed]

26. Ford, J.D.; Willox, A.C.; Chatwood, S.; Furgal, C.; Harper, S.; Mauro, I.; Pearce, T. Adapting to the Effects of Climate Change on Inuit Health. Am. J. Public Health 2014, 104, e9-e17. [CrossRef] [PubMed]

27. Finnish National Board on Research Integrity, TENK. 2019. Available online: https:/ /www.tenk.fi/en/ethical-review-in-humansciences (accessed on 1 October 2020).

28. Cardwell, F.S.; Elliott, S.J. Making the links: Do we connect climate change with health? A qualitative case study from Canada. BMC Public Health 2013, 13, 208. [CrossRef]

29. Aitken, C.; Chapman, R.; McClure, J. Climate change, powerlessness and the commons dilemma: Assessing New Zealanders' preparedness to act. Glob. Environ. Chang. 2011, 21, 752-760. [CrossRef]

30. Spein, A.R.; Pedersen, C.P.; Silviken, A.C.; Melhus, M.; Kvernmo, S.E.; Bjerregaard, P. Self-rated health among Greenlandic Inuit and Norwegian Sami adolescents: Associated risk and protective correlates. Int. J. Circumpolar Health 2013, 72. [CrossRef] [PubMed]

31. Parlee, B.; Furgal, C. Well-being and environmental change in the arctic: A synthesis of selected research from Canada's International Polar Year program. Clim. Chang. 2012, 115, 13-34. [CrossRef]

32. Kral, M.J.; Idlout, L. It's All in the Family: Well-being among Inuit in Arctic Canada. In Happiness across Cultures. Science Across Cultures: The History of Non-Western Science; Selin, H., Davey, G., Eds.; Springer: Dordrecht, The Netherlands, 2012 ; Volume 6. [CrossRef]

33. Waits, A.; Emelyanova, A.; Oksanen, A.; Abass, K.; Rautio, A. Human infectious diseases and the changing climate in the Arctic. Environ. Int. 2018, 121, 703-713. [CrossRef]

34. Palma, D.; Varnajot, A.; Dalen, K.; Basaran, I.K.; Brunette, C.; Bystrowska, M.; Korablina, A.D.; Nowicki, R.C.; Ronge, T.A. Cruising the marginal ice zone: Climate change and Arctic tourism. Polar Geogr. 2019, 42, 215-235. [CrossRef]

35. Statistic Greenland. Greenland in Figures, 2018, 15th ed.; Statistics Greenland, Government of Greenland: Nuuk, Greenland, 2018; ISBN 978-87-998113-3-5.

36. Nuttall, M. Anticipation, climate change, and movement in Greenland. Études Inuit Studies 2010, 34, 21-37. [CrossRef]

37. Barrett, B.; Charles, J.W.; Temte, J.L. Climate change, human health, and epidemiological transition. Prev. Med. 2015, 70, 69-75. [CrossRef]

38. Roser-Renouf, C.; Maibach, E.; Li, J. Adapting to the Changing Climate: An Assessment of Local Health Department Preparations for Climate Change-Related Health Threats, 2008-2012. PLoS ONE 2016, 11, e0151558. [CrossRef] [PubMed]

39. Gifford, E.; Gifford, R. The largely unacknowledged impact of climate change on mental health. Bull. At. Sci. 2016, 72, 292-297. [CrossRef] 